\title{
A Drug-Target Network-Based Approach to Evaluate the Efficacy of Medicinal Plants for Type II Diabetes Mellitus
}

\author{
Jiangyong Gu, Lirong Chen, Gu Yuan, and Xiaojie Xu \\ Beijing National Laboratory for Molecular Sciences, State Key Lab of Rare Earth Material Chemistry and Applications, \\ College of Chemistry and Molecular Engineering, Peking University, Beijing 100871, China \\ Correspondence should be addressed to Lirong Chen; lirongc@pku.edu.cn and Xiaojie Xu; xiaojxu@pku.edu.cn
}

Received 25 June 2013; Accepted 19 September 2013

Academic Editor: Francis B. Lewu

Copyright (C) 2013 Jiangyong Gu et al. This is an open access article distributed under the Creative Commons Attribution License, which permits unrestricted use, distribution, and reproduction in any medium, provided the original work is properly cited.

The use of plants as natural medicines in the treatment of type II diabetes mellitus (T2DM) has long been of special interest. In this work, we developed a docking score-weighted prediction model based on drug-target network to evaluate the efficacy of medicinal plants for T2DM. High throughput virtual screening from chemical library of natural products was adopted to calculate the binding affinity between natural products contained in medicinal plants and 33 T2DM-related proteins. The drug-target network was constructed according to the strength of the binding affinity if the molecular docking score satisfied the threshold. By linking the medicinal plant with T2DM through drug-target network, the model can predict the efficacy of natural products and medicinal plant for T2DM. Eighteen thousand nine hundred ninety-nine natural products and 1669 medicinal plants were predicted to be potentially bioactive.

\section{Introduction}

Type II Diabetes mellitus (T2DM) has been a major global health problem and affects a large population worldwide $[1,2]$. T2DM is a multifactorial and genetically heterogeneous disease caused by various risk factors such as insulin resistance, $\beta$-cell dysfunction, and obesity [2-5]. Moreover, T2DM may cause acute cardiovascular disease, retinopathy, nephropathy, neuropathy, and kidney-related complications [5-7]. Therefore, it demands effective drugs with minimal toxicity. The herbal medicines have been used for T2DM for thousands of years and accumulated a great deal of clinical experience. A herbal formula comprises several medicinal plants or animals and thus can affect the biological system through interactions between compounds and cellular targets [3, 8-17]. The main mechanisms of herbal medicines in treating T2DM are that it increases insulin secretion and the sensitivity of insulin, inhibits glucose absorption, and reduces radicals caused by lipid peroxidation [8]. However, the major problem of herbal medicines is lack of scientific and clinical data to evaluate their efficacy and safety.

Network pharmacology proposed by Hopkins is a holistic approach to understand the function and behavior of a biological system at systems level in the context of biological networks and would be the next paradigm for drug discovery [18-20]. Several efforts have been made to explore the mechanism of herbal medicines such as prediction of the active ingredients and potential targets [21-26] and screening synergistic drug combinations [11, 27, 28]. The drug-target network (DTN) which connects drugs and their target proteins is an important biological network and provides an overview of polypharmacology of drugs [29-32]. Since medicinal plants have multiple compounds and a compound would have several target proteins, the DTN may bridge the gap between medicinal plants and diseases. In this work, we developed a computational approach based on DTN to evaluate the efficacy of medicinal plants.

\section{Materials and Methods}

2.1. Data Collection and Molecular Docking. The pathogenesis of T2DM is concerned with various proteins. We retrieved the information of these proteins from KEGG Pathway database [33] and DrugBank [34] (Figure 1). The pathway of T2DM was downloaded from the KEGG website (http://www.genome.jp/dbget-bin/www_bget?hsa04930), and the information of T2DM-related proteins was collected. 


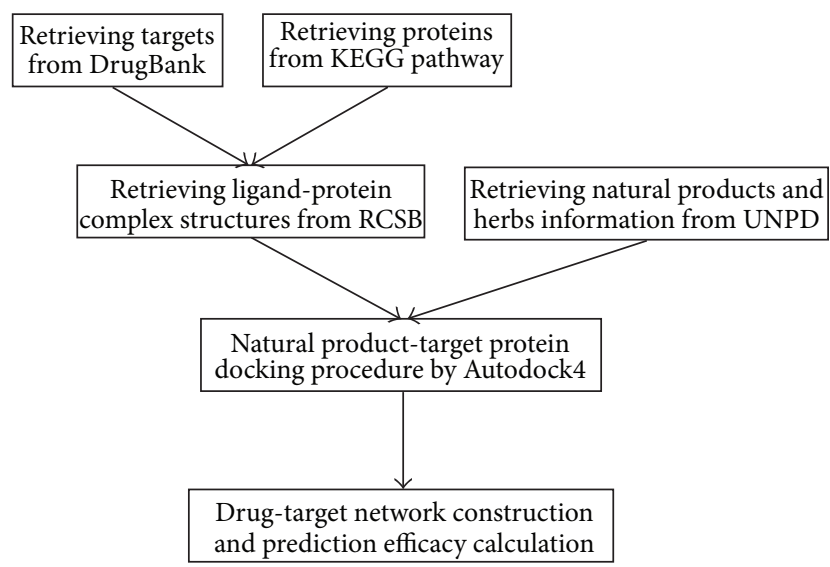

FIGURE 1: The work flow of this approach.

In DrugBank, we first retrieved the FDA-approved drugs for T2DM and then found the target proteins for each drug. Then we searched the ligand-protein complex structure (x-ray or NMR) for each protein from RCSB protein data bank (http://www.rcsb.org/pdb/home/home.do). Finally, thirty-three proteins and their information were listed in Table 1.

The 3D structures of natural products contained in medicinal plants were retrieved from the Universal Natural Product Database (UNPD) which comprised more than 208 thousands of natural products $[54,55]$. The AutoDock 4.0 [56, 57] was adopted to perform the virtual screening, and binding free energy-based docking score $\left(p K_{i}\right)$ was used to evaluate the affinity between each compound and each protein. For each protein, the hetero atoms of the ligand-protein complex structure were deleted and the polar hydrogen atoms were added. The binding site of each protein was defined as a $40 \times 40 \times 40 \AA$ cube around the original ligand with a spacing of $0.375 \AA$ between the grid points. The center of binding site was located in the center of the original ligand. The molecular docking was conducted according to the protocol described previously [58].

2.2. Drug-Target Network Construction and Analysis. The drug-target network was constructed by linking the compound with target protein if the docking score satisfied the thresholds that were used to determine whether the interaction between compound and protein was strong. According to our previous study, the thresholds were set as follow: the docking score should be greater than 7.00 and the score of original ligand of corresponding protein and the top percentage of rank of docking score should be less than $10 \%$ [54]. The edge value was the docking score of corresponding compound and protein. Finally, the DTN consisted of 32 target proteins, 18999 compounds (the UNPD ID, chemical name, formula, molecular weight, and CAS registry number of each compound were listed in Table S1, see Table S1 in Supplementary Material available online at http://dx.doi.org/10.1155/2013/203614), and 35076 edges (Supplementary Table S2). The glucocorticoid receptor
(P04150) did not have any compounds. The compounds were derived from 1669 medicinal plants distinguished by Latin names. The DTN of potentially active compounds and proteins related with T2DM was used as a bridge to build the relationship between compound or medicinal plant and T2DM.

2.3. Chemical Space Analysis. The analysis of the distribution of compounds in the chemical space was conducted by principal component analysis (PCA) module in Discovery Studio. The PCA model was built with 8 descriptors: $A \log P$, molecular weight, number of hydrogen-bond donors, number of hydrogen-bond acceptors, number of rotatable bonds, number of rings, number of aromatic rings, and molecular fractional polar surface area. The variances of PC1, PC2, and PC3 for compounds in Figure 2 were 0.488, 0.186, and 0.145, respectively. The PCA of 25 FDA-approved small-molecule drugs retrieved from DrugBank was performed in the same process as above.

2.4. Prediction Model. Natural products are multitarget agents. The average number of target proteins was 1.84 in the DTN. Therefore, we proposed that the prediction efficacy (PE) of a compound for T2DM was the sum of its all edge values (docking scores) in the DTN:

$$
\mathrm{PE}_{\text {compound }}=\sum_{j \in P} \text { score }_{j} \text {, }
$$

where $P$ was the set of proteins related to T2DM and score ${ }_{j}$ was the docking score between this compound and $j$ th protein. The $\mathrm{PE}_{\text {compound }}$ for each compound was listed in Table S3.

Similarly, the prediction efficacy of a medicinal plant was defined as the sum of PE of compounds contained in this plant:

$$
\mathrm{PE}_{\text {plant }}=\sum_{i}^{N} \mathrm{PE}_{\text {compound }},
$$

where $N$ denoted the number of compounds contained in the medicinal plant. The $\mathrm{PE}_{\text {plant }}$ for each medicinal plant was listed in Table S4.

\section{Results and Discussion}

3.1. Drug-Likeness of Medicinal Natural Products for T2DM. The natural products contained in medicinal plants for T2DM had good drug-like properties. Lipinski CA and colleagues proposed the "rule of five" (molecular weight (MW) less than $500 \mathrm{Da}$, the number of hydrogen bond acceptors (HBA) less than 10, the number of hydrogen bond donors (HBD) less than 5 , and octanol-water partition coefficient $(A \log P)$ less than five) $[59,60]$ to estimate solubility and permeability of compounds in drug discovery. That is, a compound was unlikely to be a drug if it disobeyed the rules. The mean and median of MW, HBA, HBD, and $A \log P$ of these compounds were $540.43,494.62 ; 6.3,5 ; 2.5,2$; and 4.94 , 
TABLE 1: List of 33 proteins related with T2DM for molecular docking.

\begin{tabular}{|c|c|c|c|}
\hline Index & UniProt entry & PDB entry & Protein name \\
\hline 1 & $\mathrm{O} 43451$ & 3CTT & Maltase-glucoamylase, intestinal \\
\hline 2 & P01308 & 1TYM & Insulin \\
\hline 3 & P01375 & $2 \mathrm{AZ} 5$ & Tumor necrosis factor alpha \\
\hline 4 & P04150 & $3 \mathrm{H} 52$ & Glucocorticoid receptor \\
\hline 5 & P04746 & $1 \mathrm{XDO}$ & Pancreatic alpha-amylase \\
\hline 6 & P05121 & 3UT3 & Plasminogen activator inhibitor 1 \\
\hline 7 & P06213 & $3 \mathrm{EKN}$ & Insulin receptor \\
\hline 8 & P07339 & 1LYW & Cathepsin D \\
\hline 9 & P08069 & $3 \mathrm{I} 81$ & Insulin-like growth factor 1 receptor \\
\hline 10 & P11474 & $3 \mathrm{~K} 6 \mathrm{P}$ & Steroid hormone receptor ERR1 \\
\hline 11 & P12821 & $3 \mathrm{~L} 3 \mathrm{~N}$ & Angiotensin-converting enzyme \\
\hline 12 & P13569 & 3GD7 & Cystic fibrosis transmembrane conductance regulator \\
\hline 13 & P14410 & $3 \mathrm{LPP}$ & Sucrase-isomaltase, intestinal \\
\hline 14 & P14618 & $3 \mathrm{BJF}$ & Pyruvate kinase isozymes M1/M2 \\
\hline 15 & P14735 & $3 \mathrm{E} 4 \mathrm{~A}$ & Insulin-degrading enzyme \\
\hline 16 & P19367 & 1DGK & Hexokinase-1 \\
\hline 17 & P27361 & 2ZOQ & Mitogen-activated protein kinase 3 \\
\hline 18 & P27487 & $3 \mathrm{G} 0 \mathrm{D}$ & Dipeptidyl peptidase 4 \\
\hline 19 & P27986 & $4 \mathrm{~A} 55$ & Phosphatidylinositol 3-kinase regulatory subunit alpha \\
\hline 20 & P28482 & $3 \mathrm{I} 5 \mathrm{Z}$ & Mitogen-activated protein kinase 1 \\
\hline 21 & P30613 & 2VGF & Pyruvate kinase isozymes R/L \\
\hline 22 & P35557 & 3IMX & Glucokinase \\
\hline 23 & P35568 & $2 \mathrm{Z} 8 \mathrm{C}$ & Insulin receptor substrate 1 \\
\hline 24 & P37231 & $3 \mathrm{H} 0 \mathrm{~A}$ & Peroxisome proliferator-activated receptor gamma \\
\hline 25 & P42336 & $3 \mathrm{HHM}$ & Phosphatidylinositol 4,5-bisphosphate 3-kinase catalytic subunit alpha isoform \\
\hline 26 & P42345 & 1FAP & Serine/threonine-protein kinase mTOR \\
\hline 27 & P43220 & $3 \mathrm{C} 59$ & Glucagon-like peptide 1 receptor \\
\hline 28 & P45983 & 3PZE & Mitogen-activated protein kinase 8 \\
\hline 29 & P45984 & $3 \mathrm{NPC}$ & Mitogen-activated protein kinase 9 \\
\hline 30 & P48736 & 3SD5 & Phosphatidylinositol 4,5-bisphosphate 3-kinase catalytic subunit gamma isoform \\
\hline 31 & P53779 & 3TTI & Mitogen-activated protein kinase 10 \\
\hline 32 & P62508 & 2P7A & Estrogen-related receptor gamma \\
\hline 33 & Q9BYF1 & $1 \mathrm{R} 4 \mathrm{~L}$ & Angiotensin-converting enzyme 2 \\
\hline
\end{tabular}

5.07; respectively. It indicated that most compounds would be drug-like. The wide distribution of natural products in chemical space (Figure 2) showed that there would be vast property (structural and functional) diversity. Moreover, the large overlap between natural products and 25 FDA-approved small-molecule drugs for T2DM demonstrated that natural products contained in these medicinal plants had a hopeful prospect for drug discovery for T2DM.

\subsection{Prediction Efficacy of Natural Product and Medicinal} Plant. Herb medicines could simultaneously target multiple physiological processes through interactions between multiple compounds and cellular target proteins. For example, there were 105 distinct compounds contained in Hypericum perforatum, and 21 compounds existed in DTN. The herbal medicines could influence the biological system through interactions between multi-component and multi-target and thus reverse the biological networks from disease state to health state. Since a group of compounds contained in the herbal medicine could play a therapeutic role, the dosage could be reduced to reduce toxicity and side effects. For example, UNPD43323 (ormojine), UNPD194973 (ormosinin), and UNPD194973 (strychnohexamine) were the top three potential compounds (Supplementary Table S3). ormojine, ormosinin, and strychnohexamine had 27, 24, and 23 targets, respectively. The polypharmacology of natural products was very common.

The predicted efficacy of the top twenty medicinal plants for T2DM was listed in Table 2. There were five plants (Hypericum perforatum, Ganoderma lucidum, Holarrhena antidysenterica, Celastrus orbiculatus, and Murraya euchrestifolia) where prediction efficacy was higher than 1000. We searched the literatures which reported the anti-T2DM bioactivities of the top twenty medicinal plants (Table 2) and found that 15 medicinal plants had information of definite effectiveness against T2DM. For example, Arokiyaraj and 
TABLE 2: Top twenty potential medicinal plants.

\begin{tabular}{|c|c|c|c|}
\hline Rank & Latin name & $P E_{\text {plant }}$ & Reported bioactivity \\
\hline 1 & Hypericum perforatum & 1777.81 & {$[35,36]$} \\
\hline 2 & Ganoderma lucidum & 1560.05 & [37] \\
\hline 3 & Holarrhena antidysenterica & 1147.22 & {$[38,39]$} \\
\hline 4 & Celastrus orbiculatus & 1089.44 & N/A \\
\hline 5 & Murraya euchrestifolia & 1066.97 & N/A \\
\hline 6 & Melia azedarach & 980.47 & {$[40]$} \\
\hline 7 & Datura metel & 894.36 & {$[41,42]$} \\
\hline 8 & Ficus microcarpa & 837.65 & {$[43]$} \\
\hline 9 & Tripterygium wilfordii & 785.30 & {$[44]$} \\
\hline 10 & Pachysandra terminalis & 740.38 & N/A \\
\hline 11 & Calendula officinalis & 729.77 & {$[45]$} \\
\hline 12 & Vitis vinifera & 719.77 & {$[46]$} \\
\hline 13 & Melia toosendan & 711.49 & N/A \\
\hline 14 & Mangifera indica & 677.08 & {$[47]$} \\
\hline 15 & Piper nigrum & 667.41 & {$[48]$} \\
\hline 16 & Solanum dulcamara & 667.12 & {$[49]$} \\
\hline 17 & Garcinia hanburyi & 641.41 & N/A \\
\hline 18 & Momordica charantia & 632.37 & {$[50,51]$} \\
\hline 19 & Lantana camara & 625.64 & {$[52]$} \\
\hline 20 & Ceriops tagal & 623.13 & {$[53]$} \\
\hline
\end{tabular}

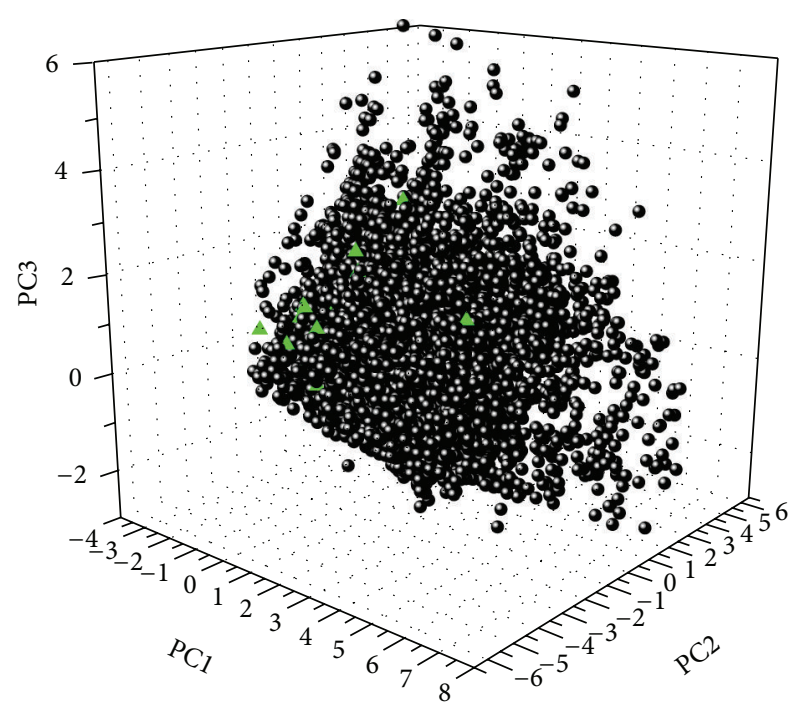

Figure 2: The distribution in chemical space according to PCA of natural products contained in medicinal plants and 25 FDAapproved drugs for T2DM. The black dots and green triangles represent natural products and FDA-approved drugs, respectively.

colleagues evaluated the antihyperglycemic activity of Hypericum perforatum in diabetic rats, and it produced significant reduction in plasma glucose level [35].

3.3. Clinical Herbal Formula. Tangminling which was a widely used herbal formula in China to treat T2DM comprised eleven medicinal herbs (Trichosanthes kirilowii, Citrus sinensis, Bupleurum chinense, Rheum officinale, Astragalus membranaceus, Pinellia ternata, Scutellaria discolor, Crataegus pinnatifida var. major, Paeonia albiflora, Prunus mume, and Picrorhiza kurroa) [3]. The prediction efficacy of each medicinal plant was 493.04, 199.26, 36.06, 29.08, 15.12, 14.80, $7.83,7.09,7.07,7.06$, and 7.04, respectively. It indicated that all plants could play a role in the treatment of T2DM. However, the prediction efficacy of eleven herbs differed considerably from each other. It meant that Trichosanthes kirilowii and Citrus sinensis played major roles (sovereign herbs). Meanwhile, The others worked as assistants which may strengthen the efficacy of sovereign herbs or reduce the toxicity.

\section{Conclusions}

Medicinal plants are potentially important for novel therapeutic drugs. It is currently estimated that approximately 420,000 plant species exist in nature [61]. However, only 10,000 of all plants have documented medicinal use [62]. Therefore, there are potentially many more important pharmaceutical applications of plants to be exploited. Traditional method (from selecting plants to separating compounds following bioassay) is time-consuming. In this work, we developed a molecular docking score-weighted prediction model based on drug-target network to evaluate the efficacy of natural products and medicinal plants for T2DM. Natural products contained in the medicinal plants would target several cellular target proteins. The prediction efficacy of this model took into account all potential interactions between multicomponents and targets. Therefore, the prediction efficacy was an overall evaluation at systems level. Fifteen out of the top twenty medicinal plants had reported bioactivity 
against T2DM in literatures. This approach may promote the research on the use of medicinal plants to treat T2DM and drug discovery from natural products.

\section{Conflict of Interests}

The authors declare that they have no conflict of interests.

\section{Acknowledgments}

This work was financially supported by the National Key Special Project of Science and Technology for Innovation Drugs (Grant nos. 2012ZX09501001-004 and 2013ZX09402202). The calculations were performed on TianHe-1(A) at the National Supercomputer Center in Tianjin.

\section{References}

[1] Y. Lin and Z. Sun, "Current views on type 2 diabetes," Journal of Endocrinology, vol. 204, no. 1, pp. 1-11, 2010.

[2] M. Stumvoll, B. J. Goldstein, and T. W. van Haeften, “Type 2 diabetes: principles of pathogenesis and therapy," The Lancet, vol. 365, no. 9467, pp. 1333-1346, 2005.

[3] J. Gu, H. Zhang, L. Chen, S. Xu, G. Yuan, and X. Xu, "Drugtarget network and polypharmacology studies of a Traditional Chinese Medicine for type II diabetes mellitus," Computational Biology and Chemistry, vol. 35, no. 5, pp. 293-297, 2011.

[4] U. Sengupta, S. Ukil, N. Dimitrova, and S. Agrawal, "Expression-based network biology identifies alteration in key regulatory pathways of type 2 diabetes and associated risk/complications," PLoS ONE, vol. 4, no. 12, Article ID e8100, 2009.

[5] S. C. Smith Jr., "Multiple risk factors for cardiovascular disease and diabetes mellitus," The American Journal of Medicine, vol. 120, no. 3, pp. S3-S11, 2007.

[6] T. Mazzone, A. Chait, and J. Plutzky, "Cardiovascular disease risk in type 2 diabetes mellitus: insights from mechanistic studies," The Lancet, vol. 371, no. 9626, pp. 1800-1809, 2008.

[7] S. Tian, Y. Li, D. Li et al., "Modeling compound-target interaction network of traditional chinese medicines for type II diabetes mellitus: insight for polypharmacology and drug design," Journal of Chemical Information and Modeling, vol. 53, no. 7, pp. 1787-1803, 2013.

[8] T. T. Zhang and J. G. Jiang, "Active ingredients of traditional chinese medicine in the treatment of diabetes and diabetic complications," Expert Opinion on Investigational Drugs, vol. 21, no. 11, pp. 1625-1642, 2012.

[9] H.-L. Zhao, P. C. Y. Tong, and J. C. N. Chan, "Traditional Chinese medicine in the treatment of diabetes," Nutritional Management of Diabetes Mellitus and Dysmetabolic Syndrome, vol. 11, pp. 15-29, 2006.

[10] J. Li, C. Lu, M. Jiang et al., "Traditional chinese medicinebased network pharmacology could lead to new multicompound drug discovery," Evidence-Based Complementary and Alternative Medicine, vol. 2012, Article ID 149762, 11 pages, 2012.

[11] S. Li, B. Zhang, and N. Zhang, "Network target for screening synergistic drug combinations with application to traditional Chinese medicine," BMC Systems Biology, 1, no. 1, article S10, 2011.
[12] T. Ma, C. Tan, H. Zhang, M. Wang, W. Ding, and S. Li, "Bridging the gap between traditional Chinese medicine and systems biology: the connection of Cold Syndrome and NEI network," Molecular BioSystems, vol. 6, no. 4, pp. 613-619, 2010.

[13] S. Li, "Network systems underlying traditional Chinese medicine syndrome and herb formula," Current Bioinformatics, vol. 4, no. 3, pp. 188-196, 2009.

[14] X. Wu, R. Jiang, M. Q. Zhang, and S. Li, "Network-based global inference of human disease genes," Molecular Systems Biology, vol. 4, article 189, 2008.

[15] S. Tian, Y. Y. Li, J. M. Wang et al., "Drug-likeness analysis of traditional chinese medicines: 2. Characterization of scaffold architectures for drug-like compounds, non-drug-like compounds, and natural compounds from traditional chinese medicines," Journal of Cheminformatics, vol. 5, no. 1, 2013.

[16] M. Y. Shen, S. Tian, Y. Y. Li et al., "Drug-likeness analysis of traditional chinese medicines: 1. Property distributions of drug-like compounds, non-drug-like compounds and natural compounds from traditional chinese medicines," Journal of Cheminformatics, vol. 4, no. 1, article 31, 2012.

[17] S. Tian, J. M. Wang, Y. Y. Li et al., "Drug-likeness analysis of traditional chinese medicines: 3. Prediction of drug-likeness using machine learning approaches," Molecular Pharmaceutics, vol. 9, no. 10, pp. 2875-2886, 2012.

[18] A. L. Hopkins, "Network pharmacology," Nature Biotechnology, vol. 25, no. 10, pp. 1110-1111, 2007.

[19] A. L. Hopkins, "Network pharmacology: the next paradigm in drug discovery," Nature Chemical Biology, vol. 4, no. 11, pp. 682690, 2008.

[20] S. Li and B. Zhang, "Traditional chinese medicine network pharmacology: theory, methodology and application," Chinese Journal of Natural Medicines, vol. 11, no. 2, pp. 110-120, 2013.

[21] W. Y. Tao, X. Xu, X. Wang et al., "Network pharmacologybased prediction of the active ingredients and potential targets of chinese herbal radix curcumae formula for application to cardiovascular disease," Journal of Ethnopharmacology, vol. 145, no. 1, pp. 1-10, 2013.

[22] S. Zhao and S. Li, "Network-based relating pharmacological and genomic spaces for drug target identification," PLOS ONE, vol. 5, no. 7, Article ID e11764, 2010.

[23] J. Gu, Y. Chen, S. Li, and Y. Li, "Identification of responsive gene modules by network-based gene clustering and extending: application to inflammation and angiogenesis," BMC Systems Biology, vol. 4, article 47, 2010.

[24] L. X. Pei, Y. W. Bao, S. Liu et al., "Material basis of chinese herbal formulas explored by combining pharmacokinetics with network pharmacology," Plos ONE, vol. 8, no. 2, 2013.

[25] A. Zhang, H. Sun, B. Yang, and X. Wang, "Predicting new molecular targets for rhein using network pharmacology," $B M C$ Systems Biology, vol. 6, article 20, 2012.

[26] J. Zhao, P. Jiang, and W. Zhang, "Molecular networks for the study of TCM pharmacology," Briefings in Bioinformatics, vol. 11, no. 4, pp. 417-430, 2009.

[27] H. Yan, B. Zhang, S. Li, and Q. Zhao, "A formal model for analyzing drug combination effects and its application in TNF$\alpha$-induced NF $\kappa$ B pathway," BMC Systems Biology, vol. 4, article 50, 2010.

[28] S. Li, B. Zhang, D. Jiang, Y. Wei, and N. Zhang, "Herb network construction and co-module analysis for uncovering 
the combination rule of traditional Chinese herbal formulae," BMC Bioinformatics, vol. 11, no. 11, article S6, 2010.

[29] M. A. Yildirim, K.-I. Goh, M. E. Cusick, A.-L. Barabási, and M. Vidal, “Drug-target network," Nature Biotechnology, vol. 25, no. 10, pp. 1119-1126, 2007.

[30] S. C. Janga and A. Tzakos, "Structure and organization of drugtarget networks: insights from genomic approaches for drug discovery," Molecular BioSystems, vol. 5, no. 12, pp. 1536-1548, 2009.

[31] J. Mestres, E. Gregori-Puigjané, S. Valverde, and R. V. Solé, "The topology of drug-target interaction networks: implicit dependence on drug properties and target families," Molecular BioSystems, vol. 5, no. 9, pp. 1051-1057, 2009.

[32] I. Vogt and J. Mestres, "Drug-target networks," Molecular Informatics, vol. 29, no. 1-2, pp. 10-14, 2010.

[33] M. Kanehisa, S. Goto, Y. Sato et al., "Kegg for integration and interpretation of large-scale molecular data sets," Nucleic Acids Research, vol. 40, no. 1, pp. D109-D114, 2012.

[34] C. Knox, V. Law, T. Jewison et al., "DrugBank 3.0: a comprehensive resource for "Omics" research on drugs," Nucleic Acids Research, vol. 39, no. 1, pp. D1035-D1041, 2011.

[35] S. Arokiyaraj, R. Balamurugan, and P. Augustian, "Antihyperglycemic effect of Hypericum perforatum ethyl acetate extract on streptozotocin-induced diabetic rats," Asian Pacific Journal of Tropical Biomedicine, vol. 1, no. 5, pp. 386-390, 2011.

[36] P. Hasanein and S. Shahidi, "Effects of Hypericum perforatum extract on diabetes-induced learning and memory impairment in rats," Phytotherapy Research, vol. 25, no. 4, pp. 544-549, 2011.

[37] Y.-H. You and Z.-B. Lin, "Protective effects of Ganoderma lucidum polysaccharides peptide on injury of macrophages induced by reactive oxygen species," Acta Pharmacologica Sinica, vol. 23, no. 9, pp. 787-791, 2002.

[38] K. M. Ali, K. Chatterjee, D. De et al., "Efficacy of aqueous extract of seed of holarrhena antidysenterica for the management of diabetes in experimental model rat: a correlative study with antihyperlipidemic activity," International Journal of Applied Research in Natural Products, vol. 2, no. 3, pp. 13-21, 2009.

[39] S. Mana, S. Singhal, N. Sharma, and D. Singh, "Hypoglycemic effect of Holarrhena antidysenterica seeds on streptozotocin induced diabetic rats," International Journal of PharmTech Research, vol. 2, no. 2, pp. 1325-1329, 2010.

[40] P. Samudram, R. Vasuki, H. Rajeshwari, A. Geetha, and P. Sathiya Moorthi, "Antioxidant and antihepatotoxic activities of ethanolic crude extract of Melia azedarach and Piper longum," Journal of Medicinal Plant Research, vol. 3, no. 12, pp. 1078-1083, 2009.

[41] B. Krishna Murthy, S. Nammi, M. K. Kota, R. V. Krishna Rao, N. Koteswara Rao, and A. Annapurna, "Evaluation of hypoglycemic and antihyperglycemic effects of Datura metel (Linn.) seeds in normal and alloxan-induced diabetic rats," Journal of Ethnopharmacology, vol. 91, no. 1, pp. 95-98, 2004.

[42] S. J. Murch, A. R. Alan, J. Cao, and P. K. Saxena, "Melatonin and serotonin in flowers and fruits of Datura metel L", Journal of Pineal Research, vol. 47, no. 3, pp. 277-283, 2009.

[43] K. Asok Kumar, M. Uma Maheswari, A. T. Sivashanmugam, V. Subhadra Devi, N. V. Prasanth, and T. K. Ravi, "Hypoglycemic effect of Ficus microcarpa leaves (Chinese Banyan) on alloxaninduced diabetic rats," Journal of Biological Sciences, vol. 7, no. 2, pp. 321-326, 2007.
[44] Y. Ge, H. Xie, S. Li et al., "Treatment of diabetic nephropathy with tripterygium wilfordii hook $\mathrm{f}$ extract: a prospective, randomized, controlled clinical trial," Journal of Translational Medicine, vol. 11, article 134, 2013.

[45] G. S. Chakraborthy, R. Arora, and C. Majee, "Antidiabetic and antihyperlipidaemic effect of hydro-alcoholic extract of calendula officinalis," International Research Journal of Pharmacy, vol. 2, no. 1, pp. 61-65, 2011.

[46] N. Orhan, M. Aslan, D. D. Orhan, F. Ergun, and E. Yeşilada, "In-vivo assessment of antidiabetic and antioxidant activities of grapevine leaves (Vitis vinifera) in diabetic rats," Journal of Ethnopharmacology, vol. 108, no. 2, pp. 280-286, 2006.

[47] A. O. Aderibigbe, T. S. Emudianughe, and B. A. S. Lawal, "Evaluation of the antidiabetic action of Mangifera indica in mice," Phytotherapy Research, vol. 15, no. 5, pp. 456-458, 2001.

[48] M. Kaleem, S. Sheema, H. Sarmad, and B. Bano, "Protective effects of Piper nigrum and Vinca rosea in alloxan induced diabetic rats," Indian Journal of Physiology and Pharmacology, vol. 49, no. 1, pp. 65-71, 2005.

[49] N. Asano, R. J. Nash, R. J. Molyneux, and G. W. J. Fleet, “Sugarmimic glycosidase inhibitors: natural occurrence, biological activity and prospects for therapeutic application," Tetrahedron Asymmetry, vol. 11, no. 8, pp. 1645-1680, 2000.

[50] C. P. Ooi, Z. Yassin, and T.-A. Hamid, "Momordica charantia for type 2 diabetes mellitus," Cochrane Database of Systematic Reviews, vol. 2, 2010.

[51] L. Leung, R. Birtwhistle, J. Kotecha, S. Hannah, and S. Cuthbertson, "Anti-diabetic and hypoglycaemic effects of Momordica charantia (bitter melon): a mini review," British Journal of Nutrition, vol. 102, no. 12, pp. 1703-1708, 2009.

[52] I. Kazmi, M. Rahman, M. Afzal et al., "Anti-diabetic potential of ursolic acid stearoyl glucoside: a new triterpenic gycosidic ester from Lantana camara," Fitoterapia, vol. 83, no. 1, pp. 142-146, 2012.

[53] P. Tiwari, A. K. Tamrakar, R. Ahmad et al., "Antihyperglycaemic activity of Ceriops tagal in normoglycaemic and streptozotocininduced diabetic rats," Medicinal Chemistry Research, vol. 17, no. 2-7, pp. 74-84, 2008.

[54] J. Y. Gu, Y. S. Gui, L. R. Chen et al., "Use of natural products as chemical library for drug discovery and network pharmacology," Plos ONE, vol. 8, no. 4, Article ID e62839, 2013.

[55] X. Qiao, T. Hou, W. Zhang, S. Guo, and X. Xu, "A 3D structure database of components from Chinese traditional medicinal herbs," Journal of Chemical Information and Computer Sciences, vol. 42, no. 3, pp. 481-489, 2002.

[56] X. Jiang, K. Kumar, X. Hu, A. Wallqvist, and J. Reifman, "DOVIS 2.0: an efficient and easy to use parallel virtual screening tool based on AutoDock 4.0," Chemistry Central Journal, vol. 2, no. 1, article 18, 2008.

[57] G. M. Morris, H. Ruth, W. Lindstrom et al., "Software news and updates AutoDock4 and AutoDockTools4: automated docking with selective receptor flexibility," Journal of Computational Chemistry, vol. 30, no. 16, pp. 2785-2791, 2009.

[58] J. Y. Gu, Q. Li, L. R. Chen et al., "Platelet aggregation pathway network-based approach for evaluating compounds efficacy," Evidence-Based Complementary and Alternative Medicine, vol. 2013, Article ID 425707, 8 pages, 2013.

[59] C. A. Lipinski, F. Lombardo, B. W. Dominy, and P. J. Feeney, "Experimental and computational approaches to estimate solubility and permeability in drug discovery and development 
settings," Advanced Drug Delivery Reviews, vol. 23, no. 1-3, pp. 3-25, 1997.

[60] C. A. Lipinski, F. Lombardo, B. W. Dominy, and P. J. Feeney, "Experimental and computational approaches to estimate solubility and permeability in drug discovery and development settings," Advanced Drug Delivery Reviews, vol. 46, no. 1-3, pp. 3-26, 2001.

[61] P. Vuorela, M. Leinonen, P. Saikku et al., "Natural products in the process of finding new drug candidates," Current Medicinal Chemistry, vol. 11, no. 11, pp. 1375-1389, 2004.

[62] J. D. McChesney, S. K. Venkataraman, and J. T. Henri, "Plant natural products: back to the future or into extinction?" Phytochemistry, vol. 68, no. 14, pp. 2015-2022, 2007. 


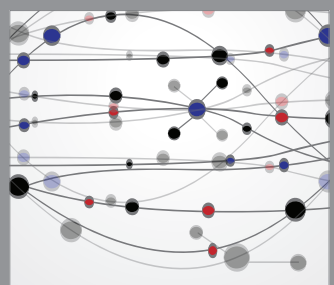

The Scientific World Journal
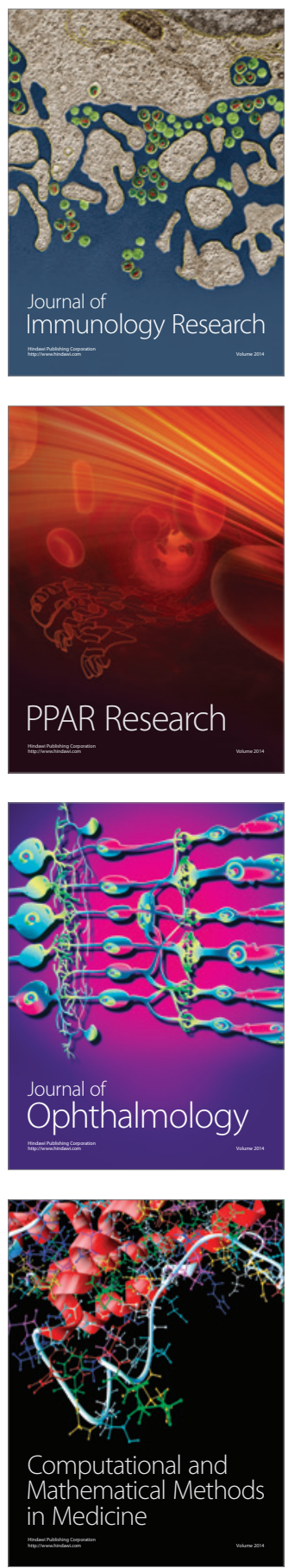

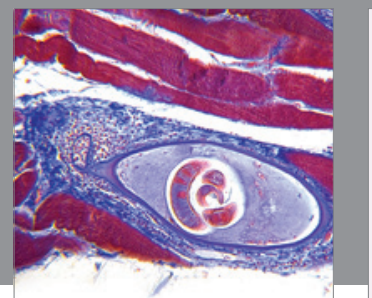

Gastroenterology

Research and Practice
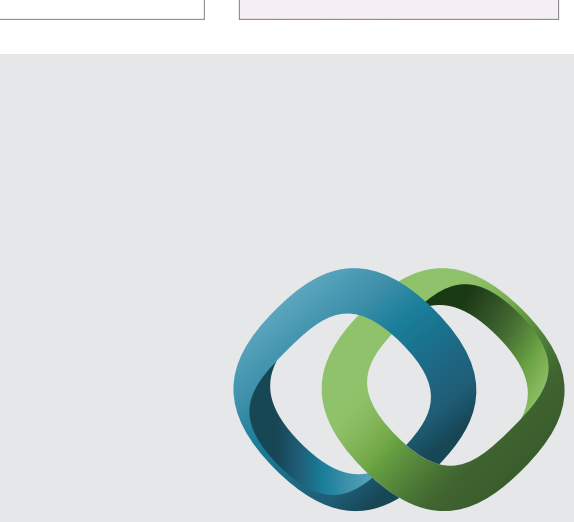

\section{Hindawi}

Submit your manuscripts at

http://www.hindawi.com
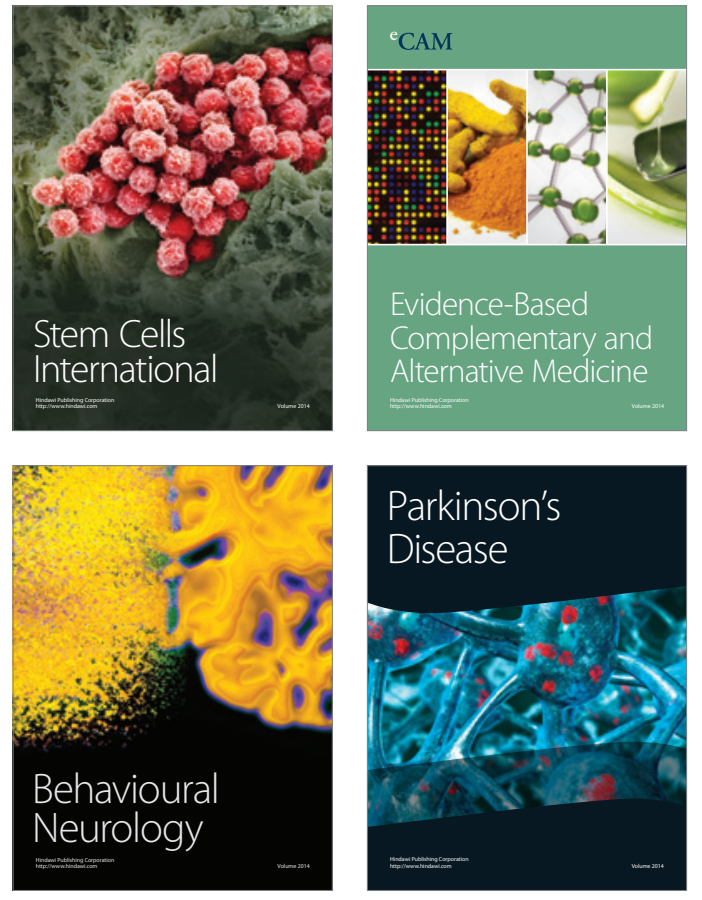
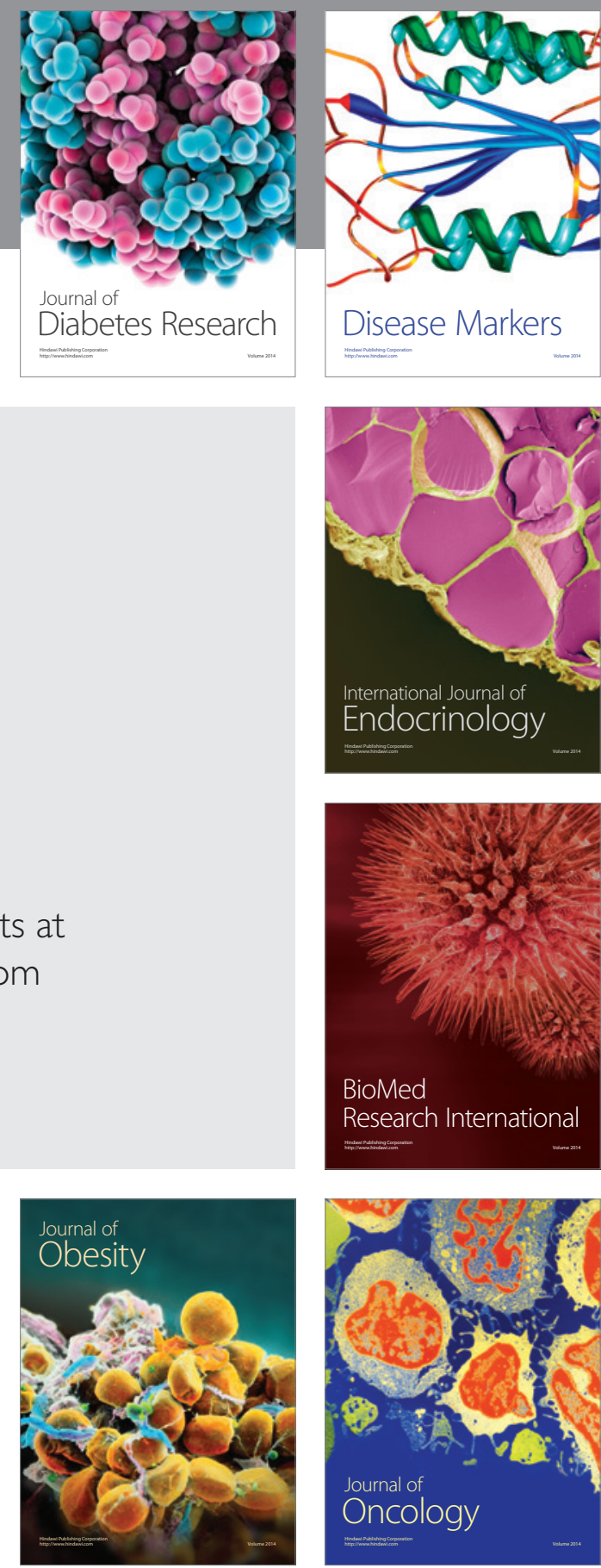

Disease Markers
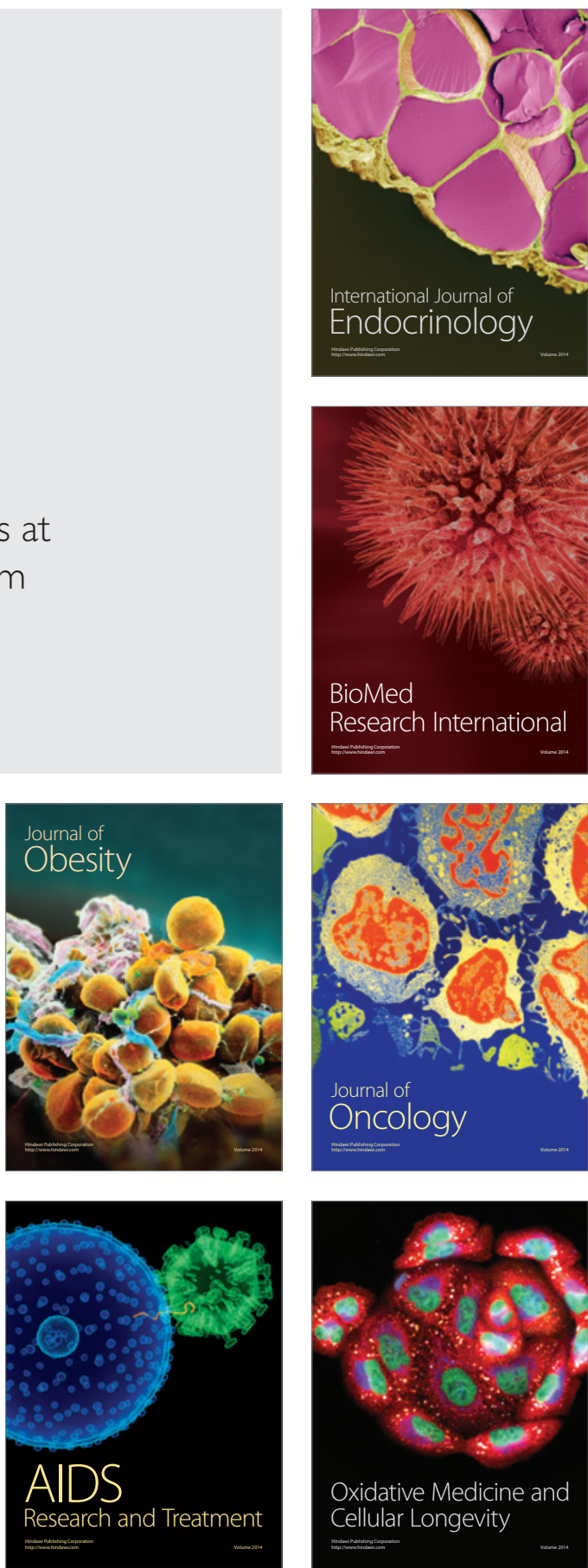